\title{
Supervisor-Subordinate (Dis)agreement on Ethical Leadership: An Investigation of its Antecedents and Relationship to Organizational Deviance
}

\author{
Maribeth Kuenzi \\ Southern Methodist University \\ Michael E. Brown \\ Pennsylvania State University-Erie
}

\author{
David M. Mayer \\ University of Michigan
}

\section{Manuela Priesemuth \\ Villanova University}

\begin{abstract}
We examine supervisor-subordinate (dis)agreement regarding perceptions of the supervisor's ethical leadership and its relationship to organizational deviance. We find that, on average, supervisors rate themselves more favorably on ethical leadership compared to how followers rate them. In addition, polynomial regression results reveal that unit-level organizational deviance is higher when there is agreement about lower levels of ethical leadership, and disagreement when supervisors rate themselves higher on ethical leadership than subordinates' ratings of the supervisors. Finally, drawing on social influence theories, we look at antecedents of (dis)agreement and find that supervisors' beliefs about themselves (that they were "better-than-average" ethical leaders) and others (their assumptions about whether the morality of their subordinates is malleable or not) are associated with self-other (dis)agreement on ethical leadership.
\end{abstract}

KEY WORDS: ethical leadership, organizational deviance, behavioral ethics, ethical biases, self-other agreement, humility

$\mathrm{O}$ rganizational deviance is voluntary behavior that violates important organizational and societal norms and threatens the well-being of an organization (Robinson \& Bennett, 1995). The annual cost of workplace deviance on the American economy has been estimated to be as high as $\$ 120$ billion for workplace violence (Deyle, 2015), \$44 billion for theft (National Retail Federation, 2015), up to $\$ 200$ billion for delinquent behavior (Bennett \& Robinson, 2000), and \$550 billion in disengaged 
employees (Gallup, 2014). Observed misconduct is not rare. In recent surveys, $41 \%$ of employees in the US (Ethics Resource Center, 2014) and approximately onethird of employees worldwide (Ethics and Compliance Initiative, 2016) observed misconduct in the workplace. In response, scholars and practitioners have called for ways to reduce deviant behavior in organizations (Lawrence \& Robinson, 2007).

Ethical leadership provides one such avenue to reduce deviance. Employees rely on ethical leaders to set the overall tone in dealing with ethical issues in organizations (Treviño, Hartman, \& Brown, 2000). Brown, Treviño, and Harrison (2005) define ethical leadership as, "the demonstration of normatively appropriate conduct through personal actions and interpersonal relationships, and the promotion of such conduct to followers through two-way communication, reinforcement, and decision making" (120). Ethical leadership is related to a variety of important outcomes including organizational deviance and counterproductive behaviors (see reviews by Bedi, Alpaslan, \& Green, 2016; Ng \& Feldman, 2015).

To date, of the many studies published on ethical leadership and important outcomes such as deviance, none have considered supervisors' perspectives of their ethical leadership. Self-perceptions, however, should be important because studies on other aspects of leadership have shown that leader and subordinate perceptions typically diverge and this lack of agreement has important implications for subordinate attitudes and behaviors (Fleenor, Smither, Atwater, Braddy, \& Sturm, 2010). Furthermore, individuals often overestimate their own ethicality leading to cognitive blind spots that can contribute to unethical behavior (Bazerman \& Tenbrunsel, 2011). To complicate matters, some of the qualities of ethical leaders such as integrity and honesty are difficult for followers to observe (Moore \& Small, 2007). Thus, it seems likely that supervisors and subordinates will frequently have differing perceptions of the supervisor's ethical leadership and such disagreement could have implications for subordinates' behavior.

Disagreement in how leaders rate their own performance (e.g., style and effectiveness) relative to how they are rated by followers (especially when leaders overestimate) is associated with less favorable follower job attitudes and performance (Atwater, Roush, \& Fischthal, 1995; Bass \& Yammarino, 1991; Yammarino \& Atwater, 1997). One explanation is that individuals who have enhanced self-perceptions may pursue tasks for which they are not well-suited or may ignore risks (Taylor \& Brown, 1988). In addition, individuals with enhanced self-perceptions are more likely to follow their own perceptions, ignoring information from others (Atwater \& Yammarino, 1997), and are more resistant to constructive feedback (Brett \& Atwater, 2001). Also, they may not be perceived as good role models (Bandura, 1977, 1986).

In this research, we set out to answer two questions. First, what happens when subordinates and supervisors do not agree about the supervisors' ethical leadership? We focus on the relationship between supervisor-subordinate disagreement on ethical leadership and organizational deviance because the link between follower-rated ethical leadership and deviance is already established in the literature. More specifically, ethical leadership is negatively related to deviant behaviors such as group deviance (Mayer, Aquino, Greenbaum, \& Kuenzi, 2012), unethical behavior (Mayer et al., 2012), as well as other negative behaviors (Bedi et al., 2016). Therefore, we first examine whether supervisor-subordinate disagreement is related to unit deviance. 
If disagreement on the supervisor's ethical leadership is associated with negative outcomes like deviance, it is also important to understand what factors might contribute to disagreement between supervisors and subordinates. Therefore, in a separate analysis, we address a second question-how are supervisors' beliefs related to disagreement? We consider how such beliefs are related to disagreement not only by affecting leaders' perceptions of themselves, but also by influencing how supervisors are viewed by their subordinates. Specifically, we hypothesize that supervisors' beliefs about their own relative performance as ethical leaders (a type of better-than-average [BTA] belief; Moore, 2007) as well as beliefs that they cannot shape and improve the ethics of others (supervisor moral entity orientation; Dweck, Chiu, \& Hong, 1995) are associated with (dis)agreement on ethical leadership.

We had three considerations when choosing these supervisor beliefs as antecedents. First, we searched for antecedents that were relevant to our social learning theoretical framework (Bandura, 1986) and could potentially affect leader role modeling which is an important component of ethical leadership (Brown et al., 2005). Second, we wanted to focus on ethics-related factors as opposed to more general features of personality that have been studied in previous ethical leadership research (Walumbwa \& Schaubroeck, 2009). Third, we looked for antecedents that would likely contribute to disagreement on ethical leadership. We believe supervisor's BTA and moral entity theory beliefs were logical choices based on these criteria. BTA beliefs are common in the moral domain (Tappin \& McKay, 2017) and, like other types of self enhancement, have potentially negative implications for ethics in general (Sedikides \& Gregg, 2008) and ethical leadership in particular (Messick \& Bazerman, 1996). BTA beliefs are often unrealistically positive (Alicke \& Govorun, 2005), so there is great potential for them to contribute to supervisor-subordinate disagreement on ethical leadership. Such beliefs are relevant to a social learning perspective on ethical leadership (Brown et al., 2005, Treviño et al., 2000) because they create ethical blind spots (Tenbrunsel \& Bazerman, 2011) which can hinder moral persons from engaging in the kind of proactive ethical role modeling that is necessary to be seen as ethical (as opposed to ethically neutral) leaders (Treviño et al., 2000).

Likewise, a moral entity orientation has obvious implications for ethics given that it reflects a supervisor's belief that ethics is immutable. From a social learning perspective, a moral entity orientation will impact how much (and how little) time supervisors dedicate to developing the ethical behavior of subordinates through core moral management behaviors (Treviño et al., 2000) such as communicating ethical standards and ethical role modeling. Given that individuals are usually not aware of their own theories about moral mutability (Dweck et al., 1995), a moral entity orientation might contribute to supervisor-subordinate disagreement by impacting subordinates' ratings but not a supervisor's own self-rating of ethical leadership.

Overall, we draw from multiple social influence theories that have been used in prior ethical leadership research to ground our hypotheses, including social exchange theory (Blau, 1964), social information processing theory (Salancik \& Pfeffer, 1978), and especially social learning theory (Bandura, 1977, 1986). Our study contributes to the ethical leadership, self-other agreement, leader humility, and ethical biases literatures. 
First, we examine whether there is a discrepancy in how supervisors rate their own ethical leadership compared to how they are rated by subordinates. Given the extensive research showing that people are not as ethical as they think they are (Tenbrunsel, Diekmann, Wade-Benzoni, \& Bazerman, 2010), it is informative to examine ethical leadership from both parties' perspectives. Second, we examine the relationship between different types of disagreement (e.g., when leader ratings are higher than follower ratings and when follower ratings are higher than leader ratings) and an important outcome, organizational deviance - a novel dependent variable to the self-other agreement literature. Third, by looking at all types of (dis)agreement, including the relatively less common leader who does not suffer from overinflated self-ratings, our study contributes to the emerging literature on leader humility (Owens, Johnson, \& Mitchell, 2013). Fourth, we add to the ethical leadership literature by linking supervisors' beliefs about ethics to (dis)agreement on ethical leadership. Furthermore, we propose that such beliefs not only have the potential to increase disagreement by affecting leaders' perceptions of themselves, but also can affect how supervisors are seen by their subordinates. Finally, this article responds to a timely and important issue in the behavioral ethics literature. Specifically, we investigate and add to the growing literature on ethical biases by empirically testing theoretical work linking ethical bias to (un)ethical leadership (Bazerman \& Tenbrunsel, 2011; Brown, 2007; Messick \& Bazerman, 1996).

\section{FOUNDATIONS OF ETHICAL LEADERSHIP}

Treviño et al. (2000) proposed ethical leadership is based on two different pillarsthe moral person and the moral manager. The moral person component focuses on desirable personal qualities of leaders such as being perceived as honest, fair, and trustworthy. The moral manager component focuses on the leader using transactional efforts such as rewards and punishments to reinforce desired behaviors and reduce undesired behaviors, as well as communicating about the importance of ethics. When a leader is strong in both of these areas, the leader is considered to be an ethical leader. Brown et al. (2005) describe ethical leadership as involving both personal demonstration and active promotion of ethical conduct to employees in the organization. These behaviors and messages of supervisors impact the (un)ethical behaviors of subordinates through social influence processes.

There are several social influence theories that have been used to understand how ethical leaders influence their followers, including social learning theory (SLT; Bandura, 1977, 1986), social exchange theory (SET; Blau, 1964), and social information processing theory (SIPT; Salancik \& Pfeffer, 1978). SLT suggests that subordinates learn from behavior modeled by supervisors as well as from the ethical standards that are communicated and reinforced in the workplace. According to SET, when supervisors engage in positive and negative behaviors towards others, they create an environment where subordinates will likely reciprocate positively or negatively. SIPT posits that individuals use cues from their work environment to understand appropriate ways to behave in the organization. Based on how many, what kind of, and how consistent these cues are, they become more or less salient 
to subordinates and impact the norms surrounding ethics. For instance, if the supervisor consistently displays unethical behavior and rewards individuals for behaving unethically these unethical norms become salient, impacting deviant behavior in subordinates (Mayer, Kuenzi, Greenbaum, Bardes, Salvador, 2009; Mayer, Nurmohamed, Treviño, Shapiro, \& Schminke, 2013). The more salient and consistent the cues are, the stronger the norms for (un)ethical behavior will be to subordinates.

\section{SUPERVISOR-SUBORDINATE (DIS)AGREEMENT AND DEVIANCE IN WORK GROUPS}

Because of the prevalence and scope of deviance in the workplace, we focus on the question of how leadership can limit or curtail costly deviant behaviors. Although deviance is an individual behavior, because of the interactions occurring within the social context of a work group, deviance can be perceived and operate as a distinct construct at the group level (see Chan, 1998, and Kozlowski \& Klein, 2000, for reviews as to how group constructs emerge). As many organizations utilize teams and/ or departments to function, it is important to examine how the leadership influences group behaviors such as deviance. Therefore, consistent with previous theory and research examining leadership, specifically ethical leadership and group deviance (e.g., Brown \& Treviño, 2006; Mayer et al., 2009; Robison \& O’Leary-Kelly, 1998) we examine employee deviance in the work group as our outcome of interest. We define group organizational deviance as voluntary behavior by members of a work group that violates the norms and threatens the well-being of the group (Robinson \& Bennett, 1995, 1997).

The relationships between ethical leadership and important outcomes in organizations such as deviance are well documented (Bedi et al., 2016; Ng \& Feldman, 2015). Although many studies have found that ethical leadership is negatively related to (un)ethical behaviors (Mayer et al., 2009; Ng \& Feldman, 2015), we believe this relationship is more complex than has been previously examined. Research on leadership and self-other agreement has found that supervisor and subordinate perceptions of the supervisor often disagree (e.g., Dansereau, Graen, \& Haga, 1975; Harris \& Schaubroeck, 1988). This disagreement is related to various employee behaviors including performance (Atwater, Ostroff, Yammarino, \& Fleenor, 1998), fairness (Jeffcoat, 2000), job satisfaction, and commitment (Szell \& Henderson, 1997). Supervisor-subordinate disagreement is also more likely to occur when examining attributes that are difficult to observe like honesty and ethics (Alicke, 1993; Brown \& Mitchell, 2010; Moore \& Small, 2007; Morgan, 1993). Thus, it is important to examine perceptions of ethical leadership from both supervisors and subordinates to assess the implications of the degree and direction of supervisor-subordinate agreement on organization deviance. Specifically, we explore two types of disagreement (overestimation and underestimation) and two types of agreement (agreement on stronger ethical leadership and agreement on weaker ethical leadership) (see Figure 1). Our primary interest is on what happens when supervisors and subordinates disagree on the ethical leadership of the supervisor, but in this research, we explore both agreement and disagreement. 


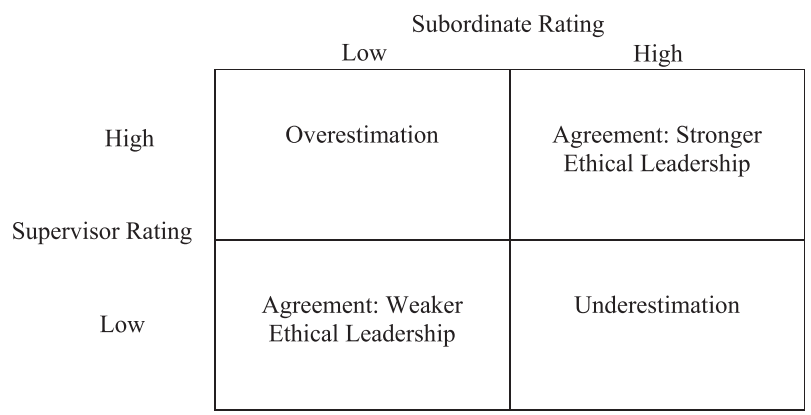

Figure 1: Types of Supervisor-Subordinate (Dis)Agreement with Corresponding Ethical Leader

Again, we focus on the unit level because members of the same unit are exposed to similar cues from their environment leading to consistent behaviors from the group (i.e., group norms; Salancik \& Pfeffer, 1978). In addition, when individuals experience consequences in a group setting, the outcomes observed by members can affect the behavior of the group as a whole (Bandura, 1986).

\section{Disagreement and Organizational Deviance}

First, we examine what happens when supervisors and subordinates disagree on their perceptions of the supervisor's ethical leadership. We do not consider the sources of (dis)agreement, but will address them in our antecedent hypotheses (see Hypotheses 3 and 4). Disagreement occurs when supervisors either overestimate or underestimate their ethical leadership in relation to their subordinates. Although supervisors and subordinates are expected to differ in their perceptions of the supervisor's ethical leadership, we are not proposing one perception is more valid than the other. Rather, we are simply interested in the type and level of (dis)agreement between the supervisors and subordinates and how that disagreement relates to deviance in the work unit. Therefore, consistent with previous research (Atwater \& Yammarino, 1997; Yammarino \& Atwater, 1997), overestimation is operationalized as the supervisor having a higher perception of his/her own ethical leadership than the perception of his/her subordinates. On the other hand, underestimation is operationalized as when the supervisor has lower perceptions of his/her own ethical leadership than the perception of his/her subordinates. We hypothesize that the type of disagreement influences whether there is a positive or negative relationship with organizational deviance.

\section{Overestimation}

The first type of disagreement is when subordinates rate the supervisor lower in ethical leadership than the supervisor rates him or herself, or overestimation by the supervisor. In this situation, the leader believes she or he is displaying strong ethical leadership, but subordinates are not perceiving such behaviors to the same degree. Generally speaking, overestimators are more likely to be content with their current performance and less likely to seek out feedback from others (Atwater \& Yammarino, 1997). These supervisors perceive themselves as stronger ethical leaders than they 
are actually seen by their subordinates, and this may come across as acting morally superior. Overestimators can suffer from an illusion of optimism, misdiagnose their own strengths and weaknesses, and fail to invest time in improving themselves because they see their own performance as acceptable (Fleenor et al., 2010).

For example, if supervisors talk confidently about ethics, but subordinates do not see them as strong ethical leaders, then according to SLT, they will not be seen as credible ethical role models (Bandura, 1977, 1986). When subordinates perceive the supervisor is acting inconsistently, they are likely to mimic any perceived negative behaviors. Even worse, due to the norms of negative reciprocity of SET (Cropanzano \& Mitchell, 2005), subordinates are more likely to engage in deviant behaviors to retaliate when they perceive supervisors are acting ethically superior towards them (Colvin, Block, \& Funder, 1995). Drawing on SIPT, when leaders are seen as inconsistent, research shows that actions "speak louder than words" and subordinates are more likely to engage in negative behaviors (Greenbaum, Mawritz, Piccolo, 2015). Overall, social influence theories point to a positive relationship between overestimation of ethical leadership and group deviance.

\section{Underestimation}

Research on self-other agreement indicates that there are instances when a subordinate rates his or her supervisor higher on various aspects of leadership than the supervisor rates him- or herself (Atwater \& Yammarino, 1992). This type of disagreement is underestimation by the supervisor. Although previous research has not specifically looked at underestimation on ethical leadership, we believe some leaders will underestimate their level of ethical leadership relative to how they are rated by subordinates. Underestimators likely receive feedback from others that they are strong ethical leaders, and yet they see themselves as having room to improve their ethical leadership. Supervisors who underestimate can be thought of as humble leaders. "Humility is grounded in a self-view of accepting that something is greater than the self and manifests in self-awareness, openness to feedback, appreciation of others, low self-focus, and self-transcendent pursuit" (Ou, Tsui, Kinicki, Waldman, Xiao, \& Song, 2014: 38). Humility is important for leaders because it can enhance their effectiveness and even neutralize the damaging effects of undesirable personality traits (Owens, Wallace, \& Walderman, 2015).

SLT suggests that humble supervisors are seen as attractive and credible role models; subordinates will mimic the behaviors of the supervisor and avoid deviant actions (Bandura, 1977, 1986). Drawing on SET, humble leaders are also perceived as likable and trustworthy so subordinates feel obligated to respond with positive reciprocity, meaning they are less likely to engage in behaviors that hurt the supervisor or the unit (Blau, 1964; Nielsen, Marrone, \& Slay, 2010). Overall, the salient cues in the environment from humble leaders will be ethically positive, with norms that deviant behavior is not tolerated.

Leader humility is related to many positive outcomes (Owens et al., 2015). Moshavi, Brown, and Dodd (2003) theorized that leaders who underestimate their potential can be perceived by subordinates as showing high levels of concern for others. This concern is thought to motivate subordinates because it can be viewed as 
altruistic leadership or leaders that gain the trust and respect of followers (Kanungo \& Mendonca, 1996). Sosik (2001) examined affective components of the leader-follower relationship and found that self-aware managers and underestimators were associated with more positive affective and performance outcomes than those who overestimated. Research on agreement between leaders and followers indicates that leaders who overestimate themselves on important leader behaviors are rated as less effective by, and generate more negative affective reactions from, their subordinates compared to leaders who underestimate (Atwater et al., 1995; Brett \& Atwater, 2001; Moshavi et al., 2003; Van Velsor, Taylor, \& Leslie, 1993).

Overall, social influence theories and previous research lead us to predict that when supervisors underestimate their ethical leadership there will be less deviance in the work group while overestimation is associated with more examples of deviant behavior. Thus, we hypothesize:

Hypothesis 1: Underestimation of ethical leadership (i.e., subordinate ratings are higher than supervisor self-ratings) will be related to less frequent unit organizational deviance than overestimation (i.e., subordinate ratings are lower than supervisor ratings).

\section{Agreement and Organizational Deviance}

Next, we examine cases where supervisors and subordinates agree on their perceptions of the supervisors' ethical leadership and their relationship to organizational deviance. We expect the two cases of agreement, agreement on stronger ethical leadership and agreement on weaker ethical leadership, will be straightforward and similar to those found in previous research examining a main effect of ethical leadership on deviance (e.g., Kacmar, Bachrach, Harris, \& Zivnuska, 2011; Mayer et al., 2012; Neves \& Story, 2015). Consistent with previous research on leader selfother agreement (Atwater et al., 1998), we predict that agreement on perceptions of ethical leadership is relevant for outcomes such as workplace deviance.

\section{Agreement on Weaker Ethical Leadership}

Agreement on weaker ethical leadership situations occurs when supervisors and subordinates both agree that the supervisor is weaker on ethical leadership. This type of agreement impacts subordinates' deviant behavior via three distinct paths. First, drawing on SLT, when supervisors perceive themselves as having low-levels of ethical leadership, they believe that they are falling short as ethical role models. Agreement on weaker ethical leadership means that supervisors are not strongly sending and subordinates are not clearly receiving messages that ethical behavior is as (or more) important than other outcomes such as achieving bottom-line outcomes (Greenbaum, Mawritz, \& Eissa, 2012). For example, weaker ethical leaders might not actively discipline employees who engage in unethical behavior, model strong ethical behavior, or emphasize the importance of maintaining high ethical standards; this can contribute to increased deviance in the work unit.

Furthermore, both supervisors and subordinates recognize that weaker ethical leaders have failed to demonstrate that they are trustworthy and fair which, according to 
SET theory, can foster negative interactions in the workplace. Norms of reciprocity suggest that subordinates will respond to poor ethical leadership by exhibiting negative behaviors, including deviant behaviors (Cropanzano \& Mitchell, 2005). Applying SIPT, when supervisors and subordinates agree that ethical leadership is absent from the workplace, strong cues develop that ethical conduct is not valued or expected in the work environment. These negative cues are adopted by the unit, leading to higher levels of deviance exhibited by subordinates (Mayer, Kuenzi, \& Greenbaum, 2010). Overall, when both supervisors and subordinates agree that weaker ethical leadership is present, there will be a stronger, positive relationship with organizational deviance.

\section{Agreement on Stronger Ethical Leadership}

In contrast, in situations where both subordinates and supervisors agree on higher ratings of ethical leadership, there should be less deviant behavior based on the same reasoning as above. According to SLT, social learning requires supervisors to actively role model, communicate, and enforce ethical standards. If supervisors make these ethical leader behaviors salient, then subordinates will get the message that deviant and other negative behaviors will not be tolerated (Brown \& Treviño, 2006). Further, ethical leaders create positive exchanges with subordinates that are characterized by perceptions of mutual trust and fairness (Potipiroon \& Fellows, 2016). Positive reciprocity by subordinates may include refraining from deviant behavior that will hurt the organization (SET; Blau, 1964). Drawing on SIPT, when supervisors demonstrate that they are ethical persons and actively manage the ethical environment, the salient norms of the group will not promote deviant behavior and subordinates are less likely to engage in acts of deviance (Mayer et al., 2010).

In sum, when supervisors and subordinates agree regarding the ethical leadership of the supervisor, less sensemaking is needed for subordinates to know the standards for ethical behavior as there is a consistent interpretation of the ethical norms in the work environment. However, we suggest that there are different types of agreement for ethical leadership of the supervisor between supervisors and subordinates and these will impact deviance differently. We posit when supervisors and subordinates agree that ethical leadership is weaker, there will be more deviant behavior in the work group. On the other hand, when supervisors and subordinates agree that ethical leadership is stronger, there will be less deviant behavior in the work group. Specifically, we hypothesize:

Hypothesis 2: Supervisor-subordinate agreement on weaker ethical leadership will be related to more frequent unit deviance than agreement on stronger ethical leadership.

\section{ANTECEDENTS OF SUPERVISOR-SUBORDINATE (DIS)AGREEMENT}

Because we propose disagreement (specifically overestimation) is related to negative outcomes in organizations, we now turn our attention to what may influence supervisor-subordinate disagreement on perceptions of ethical leadership. Social influence processes affect how messages and cues are interpreted by subordinates (Ruben \& Kim, 1975; Ruben \& Stewart, 2016). Individuals do not respond directly 
to work environments; rather, they engage in cognitive sensemaking processes involving first perception and then interpretation of cues in the work environment (Campbell, Dunnette, Lawler, \& Weick, 1970). These cues are not just words, but also actions of the supervisor, non-verbal messages, and context. These cues sent to subordinates can be intentionally created or produced accidently (Ruben \& Kim, 1975; Ruben \& Stewart, 2016). However, supervisors not only create cues in the environment, but also impact how cues are interpreted as well as their salience in the environment through social influence processes.

We believe that supervisors' beliefs about their own ethics (specifically, that they are better-than-average ethical leaders) as well as the ethics of others (that ethics is a fixed character trait that cannot be changed) are key to understanding disagreement on ethical leadership. In this study we examine two antecedents, supervisors' better-than-average beliefs and moral entity perspective, which we hypothesize impact the ethical behaviors and cues supervisors display as well as their salience to subordinates. We draw from social learning theory to explain how these supervisor beliefs impact disagreement on perceptions of ethical leadership between supervisors and subordinates.

\section{Supervisor Better-Than-Average (BTA) Beliefs}

Bazerman and Tenbrunsel (2011) provide convincing evidence that individuals are often not as ethical as they think they are. They suggest that most individuals do not want to be unethical, but individuals either overestimate their ability to do the right thing or act in some unethical manner without awareness. It is easy for individuals to fall prey to biases such as self-enhancement (overly positive view of self to maintain self-esteem) and motivated blindness (seeing what we want to see and not seeing contradictory information) when it comes to issues related to ethics. If supervisors cannot overcome their blind spots and recognize their ethical deficiencies, supervisor-subordinate agreement will be difficult to attain.

One way to examine supervisors' inflated sense of their ethical leadership is the better-than-average effect. The BTA effect is the tendency for people to favorably compare themselves to others-typically the "average" person. Although these BTA beliefs have been well established (Alicke \& Govorun, 2005; Taylor \& Brown, 1988), there are different explanations as to how BTA beliefs develop. Some research suggests that self-enhancing motivations play an important role in favorable better-than-average comparisons (Alicke \& Govorun, 2005). For example, compared to negative information (such as poor performance outcomes), positive information about ourselves is more easily remembered, seen as more important, and more frequently attributed to our own efforts (see Fiske \& Taylor, 1991 for a review). In this way, individuals' bad qualities, behaviors, and performance are overlooked, leading to inflated self-perceptions. Other researchers argue that the BTA phenomenon occurs because people know more about themselves and less about others (Moore, 2007; Moore \& Small, 2007). The BTA effect is also more likely to occur when individuals compare themselves to others on skills or attributes that are difficult to observe such as honesty or ethics (Moore \& Small, 2007). For example, most people know themselves to be generally honest, but the information they have about others' honesty is more limited. 
The literature on self-other agreement is unequivocal that self-enhancing bias beliefs produce inflated self-ratings of leadership that can lead to disagreement (Harris \& Schaubroeck, 1988). When applied specifically to ethical leadership, ethically overconfident leaders believe in their own goodness and assume that this goodness is readily apparent to others. In turn, this impacts the cues and messages that supervisors provide to subordinates.

From a social learning perspective, we propose that when supervisors believe their ethical leadership is better than average, they might not consistently engage in active moral management such as role modeling, talking about ethics, and rewarding/punishing (un)ethical behavior. Supervisors may believe they are strong ethical leaders, but without demonstrating it they will not be perceived as such by subordinates (Dunning, Heath, \& Suls, 2004; Treviño, Brown, \& Hartman, 2003). Strong BTA beliefs can also affect the attractiveness of the supervisor which is critical to being seen as an ethical role model by subordinates. Leaders who believe they are well above average can suffer from a high degree of self-admiration, arrogance, or aloofness which will not be received positively by others (Hogan, Curphy, \& Hogan, 1994; Judge, LePine, \& Rich, 2006). Thus, we predict that supervisors with stronger BTA beliefs will rate themselves more positively as ethical leaders; however, such beliefs will not necessarily translate into stronger subordinates' ratings of ethical leadership. This will contribute to supervisor-subordinate disagreement. Specifically, we hypothesize:

Hypothesis 3: Supervisor better-than-average (BTA) beliefs for ethical leadership are negatively related to supervisor-subordinate agreement on ethical leadership ratings.

\section{Supervisor Moral Entity Theorist}

Next, we examine the supervisors' beliefs about the malleability of subordinate's ethicality. According to implicit person theory, individuals have beliefs as to whether personal attributes such as morality and intelligence are fixed or malleable (Dweck et al., 1995). Individuals who believe that traits such as morality are malleable are called incremental theorists. Individuals who believe traits of individuals do not change are entity theorists. We hypothesize that supervisors who believe the ethicality of others cannot be changed, or moral entity theorists, will be viewed as weaker ethical leaders by subordinates based on the cues and messages they provide to subordinates.

Having beliefs that individuals cannot change regarding their ethics impacts not only the types of cues and messages individuals are given regarding the importance of ethics, but also the type of interactions supervisors have with different subordinates. For example, entity theorists are less likely to coach employees as well as recognize positive changes in their performance (Heslin, Latham, \& Vandewalle, 2005; Heslin, Vandewalle, \& Latham, 2006; Heslin \& VandeWalle, 2008). Supervisors with a moral entity orientation also will invest less time fostering ethical behavior of subordinates by setting and communicating ethical standards because they do not believe it would change the behavior of subordinates. When supervisors spend less time talking about how to be ethical or helping subordinates become more ethical, they will come across as weaker moral managers (Treviño et al., 2000). From a social learning perspective, such supervisors are not strong ethical role models. 
Additionally, supervisors with a moral entity orientation attribute wrongdoing to personal qualities of the transgressor. According to Heslin et al. (2005), managers with an entity theory are disinclined to alter their perceptions of an employee's performance even when presented with opposite information. This happens because entity theorists believe that an individual's attributes are innate and unalterable. In situations like this, supervisors who are moral entity theorists will have less positive exchanges on matters related to employee misconduct because they do not invest in helping subordinates develop and improve (Dweck, 1999). Dweck et al. (1995) also suggest that entity theorists will relate to others differently because they view the behavior of others as a result of enduring, static personal qualities. Supervisors with an entity theory perspective are also more likely to provide biased performance appraisals based on preconceived beliefs about individuals (Heslin et al., 2005). Subordinates will see these biased appraisals as unfair, such that supervisors with a moral entity orientation will be perceived as having less integrity (i.e., they will come across as weaker ethical leaders) than they perceive themselves. These undesirable attributes will make supervisors less attractive and, therefore, less effective as role models, according to SLT.

Overall, we propose that supervisor moral entity orientation will be negatively related to supervisor-subordinate agreement. Supervisors with a moral entity orientation believe that the morality of their subordinates is fixed, so these supervisors will be less likely to actively manage ethics, including ethical role modeling, which is important from a social learning perspective on ethical leadership. A moral entity orientation will also contribute to a leader being seen as a weaker moral person (e.g., seen as having less integrity); however, moral entity orientation should be unrelated to supervisors' self-ratings of ethical leadership because individuals are usually not aware of their own theories about moral mutability (Dweck et al., 1995). Thus, we hypothesize:

Hypothesis 4: Supervisor moral entity orientation is negatively related to supervisorsubordinate agreement on ethical leadership.

\section{SAMPLE AND PROCEDURE}

We collected data from 343 units from different organizations in the southeast US including technology, government, insurance, financial, food service, retail, manufacturing, and medical organizations. After securing IRB approval, we asked 343 business students at a large university in the southeastern United States to handdeliver survey packets to five subordinates and the supervisor of a smaller unit in an organization that each identified. Unit members were told that the students would get extra credit if they completed the surveys and were offered an aggregate summary of the results. Students were given detailed instructions and a checklist to turn in showing they had permission to hand out the surveys to employees during their shift. Respondents were provided with detailed instructions and were assured confidentiality of their responses. A postage-paid envelope was included in the packet to return the survey anonymously. 
We received a total of 1525 subordinates' responses and 334 supervisors' responses. Previous research suggests that three member responses per unit is a sufficient number to aggregate measures to the group level (Colquitt, Noe, \& Jackson, 2002; Richardson \& Vandenberg, 2005; Schneider, White, \& Paul, 1998; Tracey \& Tews, 2005). Forty-five supervisors had fewer than three subordinate responses and were therefore deleted from this sample. The researchers examined the remaining surveys to make sure they had been completed, looked for careless responses (see Meade \& Craig, 2012), and inspected the writing on the surveys to see if they had been completed by different people. We eliminated another six departments because they had surveys that were incomplete.

Thus, our final sample consisted of 1399 subordinates and 283 supervisors from 283 departments ( $M=4.94$ subordinates per department). Subordinate respondents were $41.8 \%$ male and $61.2 \%$ Caucasian (12.6\% Hispanic and $11.6 \%$ African-American). They averaged 30.3 years of age with 4.2 years of experience in the organization and 3.4 years in the unit. Supervisor respondents were 57\% male and $72.2 \%$ Caucasian (7.1\% Hispanic and 7.7\% African-American). They averaged 39.2 years of age with 9.2 years working in the organization and 7.6 years in the unit.

The subordinate survey contained measures of supervisor ethical leadership, group deviance, frequency of interaction with supervisor, and demographic questions. The supervisor survey contained measures of self-ratings of ethical leadership, better-than-average beliefs, supervisor moral entity orientation, group deviance, and demographic questions.

\section{Measures}

Except where specified below, responses for all items were made on a five-point scale $(1=$ strongly disagree, 5 = strongly agree $)$.

\section{Ethical Leadership}

Supervisor ethical leadership was rated by both supervisors and subordinates. Supervisor self-ratings of ethical leadership were measured with the 10-item ethical leadership scale developed by Brown et al. (2005). Supervisors rated the extent to which they agreed with statements such as "I talk about the importance of ethics," and "I set an example of how to do things the right way in terms of ethics." Subordinate perceptions of ethical leadership was measured using the same 10-item scale rated by subordinates in which they rated their supervisor (supervisor $\alpha=.90$, subordinate $\alpha=.97$ ); for example, "My supervisor talks about the importance of ethics."

\section{Better-Than-Average (BTA) Beliefs}

BTA beliefs were rated by the supervisor and based on work by Moore (2007). Supervisors were asked to provide a percentage that describes how their ethical leadership related to that of other managers. The item used is "I believe that my ethical leadership is stronger than the ethical leadership of _ \% of the other managers I know." 


\section{Supervisor Moral Entity Orientation}

Supervisors' rated their own moral entity orientation using the 3-item implicit theory scale developed by Dweck et al. (1995). Supervisors rated the extent to which they agreed with statements such as "A person's moral character is something that is very basic about them and it can't be changed much," and "Whether a person is responsible and sincere or not is deeply ingrained in their personality. It cannot be changed very much" $(\alpha=.81)$.

\section{Organizational Deviance}

Deviant behavior of the unit was assessed using Bennett and Robinson's (2000) 12-item Organizational Deviance Scale (ODS). Both employees and the supervisor of the unit rated the extent to which employees, as a whole, engaged in various deviant behaviors within the past year on a seven-point response format ( $1=$ never, $2=$ once, 3 = a few times, $4=$ several times, $5=$ monthly, $6=$ weekly, $7=$ daily). These were combined into one score for the unit. Example behaviors included in the scale were "taking property from work without permission" and "coming in late to work without permission" $(\alpha=.94)$.

\section{Controls}

Observational opportunities impact self-other agreement in that individuals must have enough chances to interact with the focal individual to form a reliable impression (Harris \& Schaubroeck, 1988). Therefore, frequency of interaction between supervisor and subordinate was measured and controlled for with a 3-item scale we developed. The items include "I frequently interact with my supervisor," "I frequently witness my supervisor interacting with other employees," and "There are frequent opportunities to observe my supervisor's behavior" $(\alpha=.93)$.

\section{Data Aggregation}

The unit of analysis in this study is the work unit. Thus, we aggregated subordinate responses on ethical leadership and subordinate and supervisor-rated organizational deviance to the unit level. The referent for our deviance measure was the work group (i.e., we did not ask individuals to report on the frequency of their own deviant behavior, but on deviance they observed in the group as a whole). Ethical leadership was measured at the individual level but aggregated to the group level because individuals in the same work unit are exposed to stimuli from the leader that impact the entire unit, not just one individual. In other words, we treat each of these constructs as a "shared unit property" (see Kozlowski and Klein, 2000, for a review of how these group-level constructs emerge).

We assessed the degree of agreement for ethical leadership and organizational deviance by calculating the $r_{w g}$ statistic (George \& James, 1993) as well as the intraclass correlations ICC(1) and ICC(2). These statistics indicate the extent of agreement within units, the degree of inter-rater reliability, and the stability of unitlevel means, respectively. The mean $r_{w g}$ statistic met acceptable levels (Lance, Butts, \& Michaels, 2006) for ethical leadership $\left(r_{w g}=.96\right)$, frequency of interaction 
with supervisor $\left(r_{w g}=.88\right)$, and organizational deviance $\left(r_{w g}=.97\right)$. The ICC(1) for ethical leadership was .34. and also .34 for organizational deviance. The ICC(2) for ethical leadership was .70 and .64 for organizational deviance. As all of the ICC values were statistically significant and the $r_{w g}$ values were high indicating that there was high within-group agreement, there is support for aggregation.

\section{RESULTS}

\section{Descriptive Statistics}

The means, standard deviations, reliabilities, and intercorrelations among the key variables are presented in Table 1. As predicted, organizational deviance is negatively correlated with supervisor perceptions of ethical leadership $(r=-.22)$ and subordinate perceptions of ethical leadership $(r=-.38)$. In addition, the mean value for BTA beliefs is almost $70 \%$, suggesting most leaders in our study thought their ethical leadership was better-than-average, which is to be expected. Leaders, in particular, often see themselves as above average, especially on issues related to ethics and leadership (Bazerman \& Tenbrunsel, 2011; Messick \& Bazerman, 1996). Approximately $80 \%$ of the supervisors in our sample rated themselves higher on ethical leadership than they were rated by their subordinates.

\section{Validity of Measures}

We conducted confirmatory factor analysis using MPlus 8 to ensure all the variables were distinct constructs. First, we examined the fit of a four-factor model (supervisor ethical leadership rated by subordinates, self-rated ethical leadership, supervisor moral entity orientation, and deviance). This model had an adequate fit with the data $\left(\chi^{2}=2866.84, d f=856, p<.001 ;\right.$ RMSEA $=.07$, CFI = .92). We compared the fit of the four-factor model with a three-factor model (combined subordinate-rated and self-rated ethical leadership, supervisor moral entity orientation, and deviance) and

Table 1: Means, Standard Deviations, and Correlations Among Key Measures

\begin{tabular}{|c|c|c|c|c|c|c|c|c|}
\hline Variable & $\mathbf{M}$ & SD & 1 & 2 & 3 & 4 & 5 & 6 \\
\hline $\begin{array}{l}\text { 1. Ethical Leadership } \\
\text { (supervisor rated) }\end{array}$ & 4.27 & .46 & $(.90)$ & & & & & \\
\hline $\begin{array}{l}\text { 2. Ethical Leadership } \\
\text { (subordinate rated) }\end{array}$ & 3.80 & .55 & $.34 * * *$ & $(.97)$ & & & & \\
\hline $\begin{array}{l}\text { 3. Better-Than-Average } \\
\text { Beliefs (\% Rank) }\end{array}$ & 69.10 & 30.17 & $.13^{*}$ & .03 & - & & & \\
\hline 4. Moral Entity Orientation & 3.10 & .87 & -.09 & -.11 & .06 & $(.71)$ & & \\
\hline $\begin{array}{l}\text { 5. Organization Deviance } \\
\text { (subordinate and supervisor } \\
\text { rated) }\end{array}$ & 2.27 & .70 & $-.22 * * *$ & $-.38 * * *$ & -.07 & .03 & $(.94)$ & \\
\hline $\begin{array}{l}\text { 6. Frequency of Interaction } \\
\text { with Supervisor }\end{array}$ & 3.99 & .53 & $.27 * * *$ & $.69 * * *$ & .07 & -.02 & $-.18 * *$ & $(.92)$ \\
\hline
\end{tabular}

Note. $\mathrm{N}=283 . \mathrm{M}=$ mean. $\mathrm{SD}=$ standard deviation. Values on the diagonal represent coefficient alphas. $* p<.05, * * p<.01$, $* * * p<.001$ 
a one-factor model (all combined). Neither the three-factor model $\left(\chi^{2}=3930.51\right.$, $d f=859, p<.001 ; \mathrm{RMSEA}=.11, \mathrm{CFI}=.64)$ nor the one-factor model $\left(\chi^{2}=6228.02\right.$, $d f=862, p<.001 ; \mathrm{RMSEA}=.14, \mathrm{CFI}=.37)$ fit the data well. The four-factor model fit the data better than either the three-factor model $\left(\Delta \chi^{2}=1063.67, d f=3, p \leq .001\right)$ or the one-factor model $\left(\Delta \chi^{2}=3361.18, d f=6, p \leq .001\right)$ suggesting that subordinate-rated and supervisor-rated ethical leadership, supervisor moral entity orientation, and unit deviance are distinct constructs. We do not include BTA in this model because it is assessed by a single item and, as such, should not be included in the CFA.

\section{Hypothesis Testing}

First, we found that there was a significant difference between supervisor and subordinate rated ethical leadership. The mean level of supervisor self-rated ethical leadership $(M=4.27)$ was higher than follower-rated ethical leadership $(M=3.80)$, $t(283)=13.64, p<.001$ (two-tailed); Cohen's $d=.91$.

Next, we used polynomial regression and response surface methodology to examine Hypotheses 1 and 2 (Edwards, 1993, 2001; Edwards \& Parry, 1993) to look at levels of (dis)agreement. Polynomial regression allows the impact of fit/agreement at different levels of ethical leadership and the impact of misfit/(dis)agreement resulting from higher supervisor or subordinate ethical leadership perceptions. Following Edwards and Parry (1993), this framework consists of analyzing particular features of the surfaces corresponding to quadratic equations to examine the impact of (dis) agreement or (mis)fit on unit deviance in Figure 2.

We start by estimating the following equation:

$$
Z=b_{0}+b_{1} X+b_{2} Y+b_{3} X^{2}+b_{4} X Y+b_{5} Y^{2}+e
$$

where X represents the subordinates' rating of ethical leadership, $\mathrm{Y}$ is the corresponding supervisor's self-rating of ethical leadership, and $\mathrm{Z}$ is unit deviance. We follow Edwards and Parry (1993) by examining particular features of the

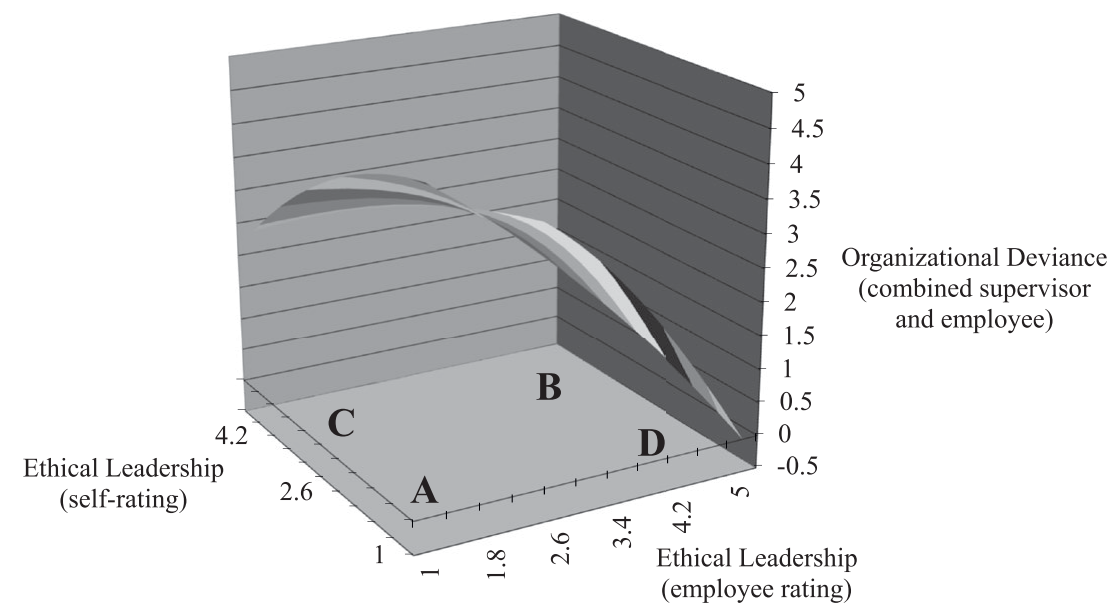

Figure 2: Supervisor-Subordinate Agreement on Ethical Leadership and Organizational Deviance 
surfaces (i.e., slope and curvature) that result from the quadratic equation to analyze the results (see Table 2 ).

Hypothesis 1 predicts that supervisor underestimation of ethical leadership will be related to less frequent unit organizational deviance than overestimation. To test this, we examined the $\mathrm{X}=-\mathrm{Y}$ line, which extends from the left-most corner of the "floor" (marked C) in Figure 2 to the right-most corner (marked D). Results indicate the slope (represented by $b_{3}-b_{4}+b_{5}$ ) and the curvature (represented by $b_{1}-b_{2}$ ) are both significant and negative $(-1.19, p<.05$ and $-.18, p<.05$, respectively), supporting Hypothesis 1 (See Table 2). Furthermore, a visual inspection of Figure 2 shows that levels of deviance are higher when leaders overestimate at lower levels of ethical leadership (e.g., when a leader rates him or herself a 3 and a follower rates him or her a 1) compared to higher levels of ethical leadership (e.g., when a leader rates him or herself a 5 and a follower rates him or her a 3). This is not surprising given that lower levels of ethical leadership are associated with more frequent occurrences of deviance.

Hypothesis 2 predicts agreement at lower-levels of subordinate and supervisor ratings of ethical leadership will be related to more organizational deviance than agreement at higher levels of ethical leadership. To test this, we examine the surface along a line that reflects equal values for $\mathrm{X}$ and $\mathrm{Y}$ (the $\mathrm{X}=\mathrm{Y}$ line). In Figure 2, this is the line that extends from the nearest corner (marked A) to the furthest corner (marked B) of the X, Y plane. Hypothesis 2 predicts that the shape of the surface along this $\mathrm{X}=\mathrm{Y}$ line will decrease moving from the nearest corner of the surface $(\mathrm{A})$ to the furthest corner (B). Results indicate that the slope (represented by $b_{1}+b_{2}$ ) is significant and negative $(-2.73, p<.01)$ supporting Hypothesis 2 (see Table 2 ).

Hypotheses 3 and 4 focus on antecedents of supervisor-subordinate agreement on ethical leadership. In order to test these hypotheses, we followed the approach outlined by Edwards (1995) for studying congruence as a dependent variable, which we outline below in five steps. First, we conducted a multivariate regression analysis so that both dependent variables - the subordinate and supervisor rating components of agreement-were tested simultaneously. The omnibus test from this analysis is significant (Wilks' $\Lambda=.56, F[8,554]=218.70, p<.001$ ) indicating that the set of antecedent variables is related to subordinate and supervisor ratings of ethical leadership considered jointly.

Table 2: Results of Polynomial Regressions of Organizational Deviance on Supervisor-Subordinate Agreement on Ethical Leadership

\begin{tabular}{|c|c|c|c|c|c|c|c|c|c|c|}
\hline & \multicolumn{6}{|c|}{$\bar{B}$} & \multicolumn{2}{|c|}{$\begin{array}{c}\text { Along the } X=Y \\
\text { line }(H 1)\end{array}$} & \multicolumn{2}{|c|}{$\begin{array}{c}\text { Along the } X=-Y \\
\text { line }(H 2)\end{array}$} \\
\hline & $\mathbf{X}$ & $\mathbf{Y}$ & $\mathbf{X}^{2}$ & XY & $\mathbf{Y}^{2}$ & $\mathbf{R}^{2}$ & $\begin{array}{c}\text { Slope } \\
b_{1}+b_{2} \\
\end{array}$ & $\begin{array}{c}\text { Curvature } \\
b_{3}+b_{4}+b_{5} \\
\end{array}$ & $\begin{array}{l}\text { Slope } \\
b_{1}-b_{2} \\
\end{array}$ & $\begin{array}{l}\text { Curvature } \\
b_{3}-b_{4}+b_{5}\end{array}$ \\
\hline $\begin{array}{l}\text { Organizational } \\
\text { Deviance (ethical } \\
\text { leader behavior) }\end{array}$ & $-1.96^{*}$ & -.77 & .06 & .23 & -.02 & $.18 * * *$ & $-2.73 * *$ & $0.27 *$ & -1.19 & -0.18 \\
\hline
\end{tabular}

Note. Following Edwards and Rothbard (1999), columns labeled X, Y, X², XY, Y² reflect unstandardized regression coefficients with all predictors entered simultaneously. The column $\mathrm{R}^{2}$ indicates the variance explained by the predictors. $\mathrm{X}=$ employee-rated ethical leadership, $\mathrm{Y}=$ supervisor self-rated ethical leadership. ${ }^{*} p<.05,{ }^{*} * p<.01, * * * p<.001$. 
Second, we examined each individual antecedent to determine if it had an equal but opposite effect on the joint supervisor-subordinate ratings. Equal but opposite effects are possible when the Wilks' $\Lambda$ for an antecedent is non-significant, but the regression coefficient for the antecedent is significant. Neither of our antecedents met these criteria. Therefore, we ruled out the possibility that equal but opposite effects were occurring.

In the third step, the relationships between each antecedent and both types of ratings are examined individually, so that we can better understand the nature of the potential (dis)agreement. To do this, we checked to see if the regression coefficients for the antecedents differed for overestimators (i.e., supervisor ratings $>$ subordinate ratings) versus underestimators (i.e., supervisor ratings $<$ subordinate ratings). We created a dummy variable and reran our analyses by adding this dummy variable to our model as well as interaction terms for each antecedent and this dummy variable. None of these interactions are significant, meaning that there are no differences in antecedent effects between overestimators and underestimators.

Fourth, we plotted the regression lines for supervisor- and subordinate-rated ethical leadership from the previous steps (using unstandardized regression coefficients) on the same set of axes. Ratings of ethical leadership are on the y-axis and values of predictors are on the X-axis: BTA beliefs (Figure 3) and supervisor moral entity orientation (Figure 4).

Finally, we examined the pattern of congruence between the lines. The results indicate that as BTA beliefs increase, supervisor-subordinate agreement on ethical leadership decreases (Figure 4). More specifically, BTA beliefs are positively related to supervisor self-rated ethical leadership (see Table 3) but unrelated to subordinate ratings of ethical leadership moving supervisors and subordinates further apart as BTA beliefs increased. Thus, Hypothesis 3 is supported.

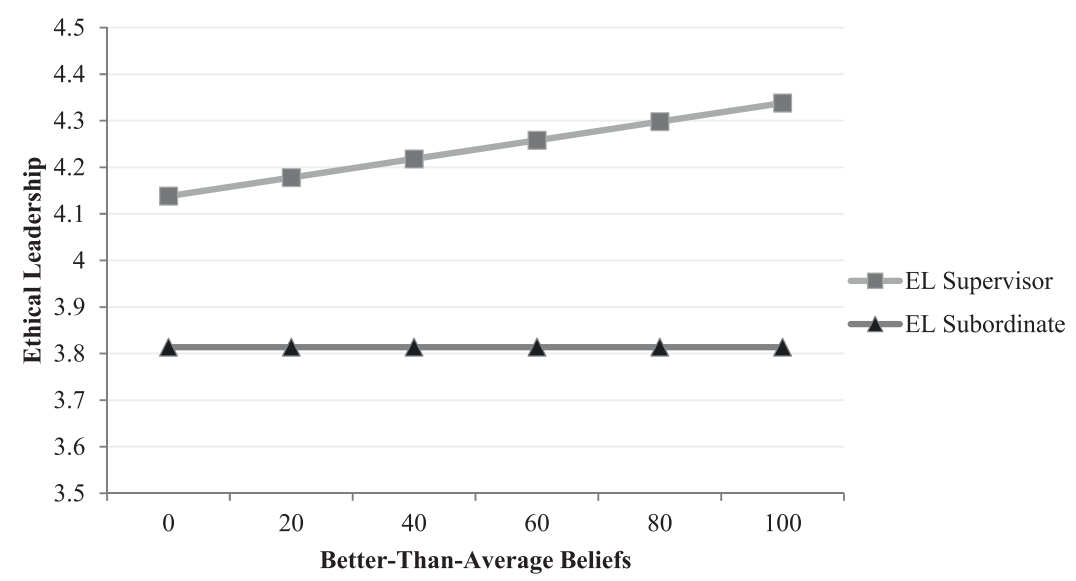

Figure 3: Better-Than-Average Beliefs and Supervisor-Subordinate Agreement on Ethical Leadership

Note. Unstandardized coefficients were used to plot regression lines. Line shown is when Moral Entity Orientation is at its mean value. 


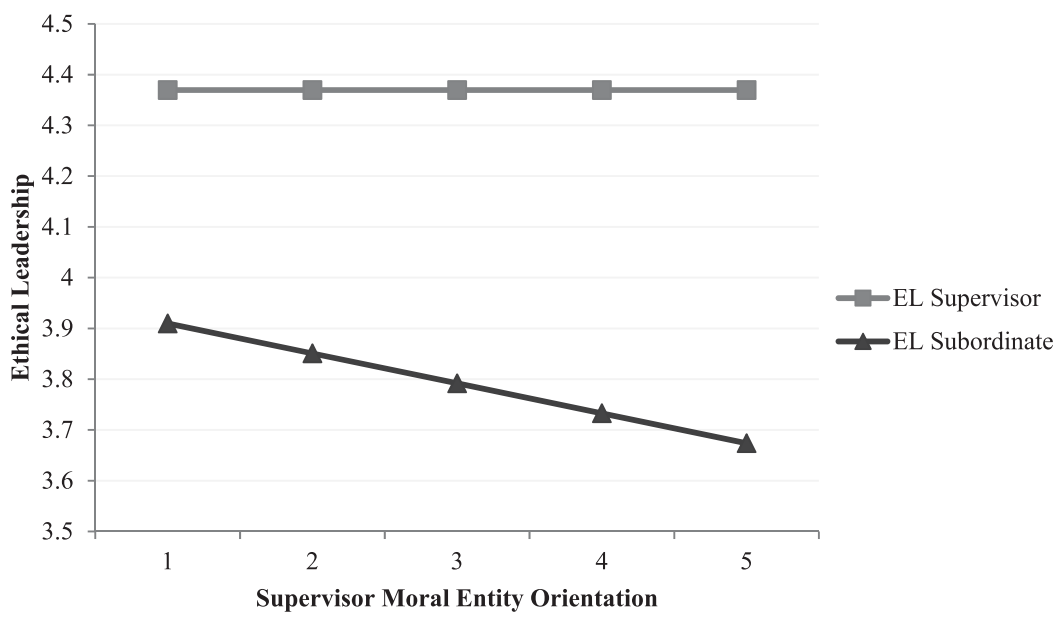

Figure 4: Supervisor Moral Entity Orientation and Supervisor-Subordinate Agreement on Ethical Leadership

Note. Unstandardized coefficients were used to plot regression lines. Line shown is when better-than-average beliefs are at their mean value.

In terms of Hypothesis 4, as supervisor moral entity orientation increased, supervisor-rated ethical leadership remained unchanged while subordinate-rated ethical leadership decreased (see Figure 4). Thus, Hypothesis 4 is supported.

\section{DISCUSSION}

In this research, we studied antecedents (better-than-average beliefs, supervisor moral entity orientation) and an outcome (unit-level deviance) of supervisor-subordinate disagreement on ethical leadership. We found that supervisors, on average, rate themselves higher on ethical leadership than employees rate them. Also, we hypothesized and found that deviance is higher when subordinates and supervisors agree the supervisor is weaker on ethical leadership as well as when subordinate ratings of ethical leadership are lower than supervisor self-ratings (overestimation). Deviance is lower when supervisors underestimate their ethical leadership compared to subordinates and when subordinates and supervisors agree the supervisor is stronger on ethical leadership. As for antecedents of (dis)agreement, we found that better-than-average beliefs and supervisor moral entity orientation are negatively related with agreement

Table 3: Relationships Between Better-Than-Average Beliefs and IPT-Moral on Supervisor Self-Ratings and Subordinate Ratings of Ethical Leadership

\begin{tabular}{lcc}
\hline \hline Variable & $\begin{array}{c}\text { Supervisor Self-Rated } \\
\text { Ethical Leadership }\end{array}$ & Subordinate-Rated \\
\hline Better-Than-Average Beliefs & $.13^{*}$ & Ethical Leadership \\
Supervisor Moral Entity Orientation & -.09 & .00 \\
$R^{2}$ & .11 & $-.10^{*}$ \\
\hline \hline
\end{tabular}

Note. $N=283$; Standardized regression coefficients (Betas) are shown. $* p<.05$. 
on ethical leadership. Overall, our findings are consistent with social learning and other influence perspectives on ethical leadership (e.g., Brown et al., 2005).

\section{Theoretical Implications}

The results of this research have implications for multiple literatures. First, we extend recent work on ethical biases, particularly blind spots (Tenbrunsel et al., 2010), to ethical leadership by exploring whether leaders believe they are more ethical than they really are (i.e., compared to how they are really seen by others). We found that, on average, supervisors overestimate their own ethical leadership relative to how they are rated by their subordinates. This is important because previous research on self-other agreement (Atwater et al., 1997; Harris \& Schaubroeck, 1988) and ethical bias (Bazerman \& Tenbrusnel, 2011) has not explicitly examined (dis)agreement among supervisors and subordinates on ethical leadership. Our findings demonstrate that examining both leader and follower perceptions can complement the traditional follower-centered approach used in most ethical leadership research.

We also contribute to the ethical leadership and deviance literatures by highlighting the relationship between (dis)agreement and deviance. Prior research has shown that ethical leadership (as rated by subordinates) is negatively related to deviance (Mayer et al., 2009; Mayer et al., 2013). Our results indicate this relationship is more complicated when we take into account both the supervisors' and subordinates' perceptions of ethical leadership. When supervisors and subordinates agree on the supervisors' ethical leadership, the results mimic the main effects of subordinate perceptions of ethical leadership on deviance. However, when we look at disagreement, the results are more nuanced with overestimation associated with greater deviance, and underestimation related to less deviance. We attribute these findings, in part, to leader humility.

According to Owens and colleagues (2013) accurate self-perception (i.e., selfother perceptions are in agreement) is a core dimension of humility. Our findings, however, show that accuracy does not always correlate with humble, effective leadership; such as when leaders and followers agree that the leader is a weaker ethical leader. Furthermore, we found that some inaccurate perceptions are beneficial; specifically, underestimation which is associated with lower levels of deviance (see Figure 3). Our research adds to the emerging literature on humility (Owens et al., 2013; Owens et al., 2015; Owens \& Hekman, 2012) and suggests future research is needed to clarify the relationships between humility, (dis)agreement, and important outcomes like deviance.

Given the potential for negative outcomes such as deviance, we examined antecedents linking supervisor beliefs about ethics (better-than-average beliefs and moral entity perspective) to (dis)agreement on the supervisor's ethical leadership. These antecedents new to the self-other agreement literature were chosen, in part, because of their relevance to a social learning perspective on ethical leadership. In line with our predictions, we found both better-than-average beliefs and moral entity orientation were negatively related to agreement on ethical leadership. However, the form of disagreement for each antecedent differed. Disagreement based on BTA beliefs was driven by supervisor self-ratings (BTA beliefs were unrelated to follower perceptions); 
the opposite was true for moral entity orientation, which was related to follower perceptions but not supervisor self-perceptions.

It is possible that this pattern of results can be explained by the shared foci of the beliefs and ratings. We found that supervisors' beliefs about their own ethics impacted how they rated themselves as ethical leaders (i.e., both have a common focus on how supervisors see themselves). Supervisors' beliefs about the ethics of others were related to how the supervisors were rated by subordinates on ethical leadership (i.e., beliefs about others can affect how supervisors behave toward and are ultimately perceived by others). Our findings suggest that supervisor beliefs can produce disagreement by influencing follower perceptions. This is a novel contribution to the literature on antecedents of (dis)agreement because previous research has focused on identifying relationships between leader individual differences (e.g., personality) and leader self-ratings as well as follower individual differences and follower-ratings (Atwater \& Yammarino, 1997). Future research should explore other antecedents and identify the different ways they can contribute to disagreement on ethical leadership. For example, there might be follower individual differences that are related to (dis)agreement on ethical leadership and deviant behaviors (e.g., followers who are complicit in workplace deviance might be subject to a type of motivated reasoning that makes it harder for them to see ethical leadership behaviors).

Finally, our study addresses the paucity of self-other agreement research in the area of ethics, and in particular, ethics and leadership (Brown \& Mitchell, 2010). We found that different types of agreement and disagreement on ethical leadership were related to deviance. The findings from the broader self-other agreement literature suggest supervisor-subordinate (dis)agreement on other phenomenon might be relevant. Overall, this study represents a first step toward answering these types of questions.

\section{Practical Implications}

There are also important practical implications of the present work. In our sample, almost $80 \%$ of supervisors rated themselves as more ethical than their subordinates rated them, which suggests that overestimating personal ethical leadership might be an epidemic. In this study we found that overestimation is related to greater levels of workplace deviance. Overestimation of ethical leadership can contribute to a negative relationship with subordinates, interfere with the benefits of being an ethical leader, and inhibit self-improvement of supervisors. These results are in line with research in other areas. For instance, subordinates receiving feedback from leaders who are overestimators are more likely to experience feelings of anger and discouragement (Brett \& Atwater, 2001). Also, the relationship between transformational leadership and important outcomes (e.g., leader's performance evaluations and promotion potential) is strongest when leader self-ratings are most closely related to followers' ratings and weakest when leader ratings exceed follower ratings (Atwater \& Yammarino, 1992). Organizations should seek to identify supervisors who overestimate their ethical leadership and utilize self-awareness training (e.g., as part of training to develop leader humility; Owens et al., 2015) to help leaders become more aware of how others perceive their actions as well as to understand the importance of these 
perceptions on important organizational outcomes and subordinate behaviors. However, leaders who overestimate might fail to see the benefits of such training, especially if they see themselves as strong ethical leaders already. Future research should look at the impact of self-other (dis)agreement, particularly overestimation, on training effectiveness.

Supervisors also need coaching on how to seek feedback from subordinates given that negative feedback seeking is related to perceived effectiveness. Yet, research suggests that individuals are more likely to seek feedback from their superiors than from their peers or subordinates, because feedback from superiors is more instrumental in obtaining success (Ashford \& Tsui, 1991). Nevertheless, providing feedback to leaders regarding how they are perceived by their followers enhances subsequent leader-follower agreement (Atwater, Waldman, Atwater, \& Cartier, 2000). Obtaining this feedback from subordinates can be problematic in that subordinates are reluctant to share with someone whom they perceive to be less ethical. For instance, Atwater et al. (2000) found that when leaders received negative feedback they were more cynical and had less commitment to subordinates. Leaders may also discount subordinate feedback because they think subordinates do not have sufficient information or understanding to provide feedback or their feedback can be politically motivated (Ashford, Blatt, \& Vandewalle, 2003). Again, organizations could provide training for both subordinates and leaders on how to effectively provide and use 360-degree feedback.

Last, but not least, our results show that having a supervisory moral entity orientation is associated with greater disagreement on ethical leadership (specifically due to lower follower ratings of ethical leadership). This has potential implications for leader selection and development. Organizations should take care in selecting individuals with strong moral entity beliefs and placing them in positions of leadership. Would-be ethical leaders must believe that they are capable of being effective moral managers who have the power to influence the ethical conduct of those they lead. Training, education, and other leader development activities can help leaders understand that individuals' ethics can be influenced, particularly through the demonstration of strong ethical leader behavior which has been shown effective across many studies in promoting ethical, and reducing unethical, conduct of subordinates (Ng \& Feldman, 2015).

\section{Limitations and Future Directions}

Although there are a number of strengths of the current research, there are also important limitations. First, although we draw on social influence theories, we do not directly measure the mechanisms the theories propose. For instance, we draw on SLT (Bandura, 1977, 1986) but we did not directly measure any role-modeling behaviors. Our results are consistent with SLT; however, we cannot state conclusively that our results are due to social learning processes without directly measuring the processes. Further, the importance of each mechanism might vary depending on the antecedents and outcomes in question. For example, social learning seems more important to understanding the antecedents of supervisor-subordinate (dis)agreement while social exchange might provide a more powerful explanation of linking such 
(dis)agreement to outcomes. Future research should examine the different roles and differential effects of social influence theories of ethical leadership on different antecedents and outcomes of (dis)agreement.

A second limitation is that we only examined a single dependent variableorganizational deviance. Recent research has expanded the nomological network of ethical leadership, relating it to organizational citizenship behaviors, voice, and other negative outcomes such as relationship conflict and unethical behavior (Ng \& Feldman, 2015). Thus, in future research, it would be interesting to examine additional outcomes of (dis)agreement, especially positive ones such as prosocial or whistle-blowing behavior. Furthermore, researchers might also consider whether (dis)agreement on ethical leadership influences (dis)agreement on supervisor and subordinate perceptions on outcomes. For example, perhaps disagreement on ethical leadership explains why senior managers and rank and file employees have differing views about key dimensions of organizational ethics (Treviño, Weaver, \& Brown, 2008).

A third limitation is that all data, although drawn from multiple sources, are crosssectional, so we cannot establish causality. Although previous research has demonstrated a causal relationship between follower-rated ethical leadership and deviance, future research in a longitudinal setting is necessary in order to confirm our findings.

Fourth, this study looked at supervisors and their immediate subordinates. Thus, we are unable to account for differences in levels of management that might influence our findings. We know that follower perceptions of leaders vary based on distance between the leader and follower (Antonakis \& Atwater, 2002). While we controlled for frequency of interaction, would we find the same level of overestimation as well as the same relationships between disagreement, antecedents, and outcomes if we surveyed executives and more distant employees (i.e., those who are not direct reports)? Along this line, previous research has found a discrepancy between how top managers and lower-level employees view their organization's ethical performance with more favorable views prevailing at the top and more negative views residing at the bottom (Treviño et al., 2008). Thus, we expect that disagreement in leader-subordinate perceptions of executive ethical leadership will be greater for executive and lower-level employees compared to executives and middle- or senior-level employees.

Finally, we only considered supervisor-subordinate (dis)agreement on perceptions of the supervisor; however, disagreement among other raters (e.g., supervisors, subordinates, superiors, and peers) might also be important in terms of predicting relevant outcomes. Future research is necessary to determine how much (dis)agreement exists between other rating sources. Does (dis)agreement among rating groups share similar antecedents and consequences? At the executive level, ethical leadership researchers might consider studying (dis)agreement among an organization's internal and external constituencies in general, or specific stakeholder groups in particular (Brown \& Mitchell, 2010). This type of research might provide new insights into corporate social responsibility and descriptive stakeholder theory and research.

While we examined two antecedents of supervisor-subordinate ethical leadership disagreement, there is more work to be done to add to this stream of research. An additional supervisor variable would be to examine how subordinate perceptions of behavioral integrity (Simons, 2002) — the supervisor enacts the same values he 
or she espouses - are associated with perceptions of and (dis)agreement on ethical leadership. Future research could also examine subordinate individual differences as antecedents. For instance, morally disengaged subordinates or those with low moral identity may perceive the supervisor as less ethical because they are less likely to recognize the leader's ethical behaviors. Furthermore, we collected moral entity beliefs only from the supervisor, but it could also be valuable to see if subordinate moral entity beliefs impact their perceptions of ethical leadership and (dis)agreement.

It would also be interesting to investigate the relative impact of different types of (dis)agreement on unit deviance across settings (e.g., across different types of organizations and industries). For instance, we found that both agreement on stronger ethical leadership and underestimation are related to lower levels of deviance. Are they always important? When and why might one be more influential than the other? Similarly, we found that disagreement on weaker ethical leadership and overestimation are related to higher levels of deviance. Again, under what circumstances might one be more strongly related to deviance than the other? Conducting an experiment to control and compare across the groups would shed more light on the issue and provide better guidance to organizations.

Finally, another avenue would be to examine contextual variables such as national culture to see how they impact (dis)agreement. Leaders from individualistic cultures are more likely to have inflated self-ratings (see Fleenor et al., 2010). Thus, the importance of being a humble leader might vary depending on whether a culture more strongly values individualism or collectivism (Hofstede, 1980). Humility might be essential for leading in collectivist cultures, and thus produce more positive outcomes when it is present (and more negative outcomes when it is absent).

\section{CONCLUSION}

The present research adds to the ethical leadership literature by examining a type of leader ethical bias: specifically, the phenomenon that 'we are not as ethical as we think we are' (Tenbrunsel et al., 2010) and how this is associated with deviance in organizations. To date, research has focused only on subordinate perceptions of ethical leadership, yet supervisors and subordinates differ in their perceptions of leadership. Our results indicate that when supervisors overestimate their ethical leadership compared to subordinates, it is related to higher deviant behavior in organizations. By examining factors that affect the (dis)agreement between subordinates and supervisors, we begin to shed light on ways to foster greater consistency between supervisor and subordinate perceptions of ethical leadership, and ultimately reduce workplace deviance.

\section{REFERENCES}

Alicke, M. D. 1993. Egocentric standards of conduct evaluation. Basic and Applied Social Psychology, 14: 171-192.

Alicke, M. D., \& Govorun, O. 2005. The better-than-average effect. In M. D. Alicke, D. Dunning, \& J. Krueger (Eds.), The self in social judgment: 85-106. New York: Psychology Press. 
Antonakis, J., \& Atwater, L. 2002. Leader distance: A review and a proposed theory. The Leadership Quarterly, 136: 673-704.

Ashford, S. J., Blatt, R., \& Vandewalle, D. 2003. Reflections on the looking glass: A review of research on feedback-seeking behavior in organizations. Journal of Management, 29: 773-799.

Ashford, S. J., \& Tsui, A. S. 1991. Self-regulation for managerial effectiveness: The role of active feedback seeking. Academy of Management Journal, 34: 251-280.

Atwater, L. E., Ostroff, C., Yammarino, F. J., \& Fleenor, J. W. 1998. Self-other agreement: Does it really matter? Personnel Psychology, 51: 577-598.

Atwater, L., Roush, P., \& Fischthal, A. 1995. The influence of upward feedback on selfand follower ratings of leadership. Personnel Psychology, 48: 35-59.

Atwater, L. A., Waldman, D., Atwater, D., \& Cartier, P. 2000. An upward feedback field experiment. Supervisors' cynicism, follow-up and commitment to subordinates. Personnel Psychology, 53: 275-297.

Atwater, L., \& Yammarino, F. J. 1997. Antecedents and consequences of self-other rating agreement: A review and model. In G. Ferris (Ed.), Research in personnel and human resources management: 121-174. Greenwich, CT: JAI.

Atwater, L., \& Yammarino, F. J. 1992. Does self-other agreement on leadership perceptions moderate the validity of leadership and performance predictions? Organizational Dynamics, 25: 35-44.

Bandura, A. 1977. Social learning theory. Englewood Cliffs, NJ: Prentice-Hall.

Bandura, A. 1986. Social foundations of thought and action. Englewood Cliffs, NJ: Prentice-Hall.

Bass, B. M., \& Yammarino, F. J. 1991. Congruence of self and others' leadership ratings of naval officers for understanding successful performance. Applied Psychology: An International Review, 40: 437-454.

Bazerman, M. H., \& Tenbrunsel, A. E. 2011. Blind spots. Princeton, NJ: Princeton University Press.

Bedi, A., Alpaslan, C. M., \& Green, S. A. 2016. A meta-analytic review of ethical leadership outcomes and moderators. Journal of Business Ethics, 139: 517-536.

Bennett, R., \& Robinson, S. 2000. Development of a measure of workplace deviance. Journal of Applied Psychology, 85: 349-360.

Blau, P. M. 1964. Exchange and power in social life. New York: John Wiley.

Brett, J. F., \& Atwater, L. E. 2001. $360^{\circ}$ Feedback: Accuracy, reactions, and perceptions of usefulness. Journal of Applied Psychology, 86: 930-942.

Brown, M. E. 2007. Misconceptions of ethical leadership: How to avoid potential pitfalls. Organizational Dynamics, 36: 140-155.

Brown, M. E., \& Mitchell, M. S. 2010. Ethical and unethical leadership: Exploring new avenues for future research. Business Ethics Quarterly, 20: 583-616.

Brown, M. E., \& Treviño, L. K. 2006. Ethical leadership: A review and future directions. The Leadership Quarterly, 176: 595-616.

Brown, M. E., Treviño, L. K., \& Harrison, D. 2005. Ethical leadership: A social learning perspective for construct development and testing. Organizational Behavior and Human Decision Processes, 97: 117-134.

Campbell, J. P., Dunnette, M. D., Lawler, E. E., \& Weick, K. E. 1970. Managerial behavior, performance, and effectiveness. New York: McGraw-Hill.

Chan, D. 1998. Functional relations among constructs in the same content domain at different levels of analysis: A typology of composition models, Journal of Applied Psychology, 83: 234-246. 
Colquitt, J. A., Noe, R. A., \& Jackson, C. L. 2002. Justice in teams: Antecedents and consequences of procedural justice climate. Personnel Psychology, 55: 83-109.

Colvin, C. R., Block, J., \& Funder, D. 1995. Overly positive self-evaluations and personality: Negative implications for mental health. Journal of Personality and Social Psychology, 68: $1152-1162$.

Cropanzano, R., \& Mitchell, M. S. 2005. Social exchange theory: An interdisciplinary review of conceptual and definitional issues. Journal of Management, 31: 874-900.

Dansereau, F., Graen, G. B., \& Haga, W. 1975. A vertical dyad linkage approach to leadership in formal organizations. Organizational Behavior and Human Performance, 13: $46-78$.

Deyle, E. 2015. Global retail theft barometer. Thorofore, NJ: Checkpoint Systems.

Dunning, D., Heath, C., \& Suls, J. M. 2004. Flawed self-assessment: Implications for health, education, and the workplace. Psychology in the Public Interest, 5: 69-106.

Dweck, C. S., Chiu, C. Y., \& Hong, Y. Y. 1995. Implicit theories: Elaboration and extension of the model. Psychological Inquiry, 6: 322-333.

Dweck, C. S. 1999. Self theories: Their role in motivation, personality, and development. Philadelphia, PA: Psychology Press.

Edwards, J. 1993. Problems with the use of profile similarity indices in the study of congruence in organizational research. Personnel Psychology, 46: 641-665.

Edwards, J. R. 1995. Alternatives to difference scores as dependent variables in the study of congruence in organizational research. Organizational Behavior and Human Decision Processes, 64: 307-324.

Edwards, J. 2001. Alternatives to difference scores: Polynomial regression analysis and response surface methodology. In F. Drasgow \& N. W. Schmitt (Eds.), Advances in measurement and data analysis: 350-400. San Francisco, CA: Jossey-Bass.

Edwards, J., \& Parry, M. 1993. On the use of polynomial regression equations as an alternative to difference scores in organizational research. Academy of Management Journal, 36: 1577-1613.

Ethics and Compliance Initiative. 2016. 2016 global business ethics survey: Measuring risk and promoting workplace integrity. Arlington, VA: Ethics and Compliance Initiative.

Ethics Resource Center. 2014. National business ethics survey of the U.S. workforce. Arlington, VA: Ethics Resource Center.

Fiske, S. T., \& Taylor, S. E. 1991. Social cognition. New York: McGraw-Hill.

Fleenor, J. W., Smither, J. W., Atwater, L. E., Braddy, P. W., \& Sturm, R. E. 2010. Self-other rating agreement in leadership: A review. The Leadership Quarterly, 216: 1005-1034.

Gallup. 2014. State of the global workplace. Washington, DC: Gallup.

George, J. M., \& James, L. R. 1993. Personality, affect, and behavior in groups revisited: Comment on aggregation, level of analysis, and a recent application of within and between analysis. Journal of Applied Psychology, 78: 798-804.

Greenbaum, R. L., Mawritz, M. B., \& Eissa, G. 2012. Bottom-line mentality as an antecedent of social undermining and the moderating roles of core self-evaluations and conscientiousness. Journal of Applied Psychology, 972: 343-359.

Greenbaum, R. L., Mawritz, M. B., \& Piccolo, R. F. 2015. When leaders fail to "walk the talk:" Supervisor undermining and perceptions of leader hypocrisy. Journal of Management, 41: 929-956.

Harris, M. M., \& Schaubroeck, J. 1988. A meta-analysis of self-supervisor, self-peer, and peer-supervisor ratings. Personnel Psychology, 41: 43-62.

Heslin, P. A., Latham, G. P., \& Vandewalle, D. 2005. The effect of implicit person theory on performance appraisals. Journal of Applied Psychology, 90: 842-856. 
Heslin, P. A., Vandewalle, D., \& Latham, G. P. 2006. Keen to help? Managers' implicit person theories and their subsequent employee coaching. Personnel Psychology, 59: 871-902.

Heslin, P. A., \& Vandewalle, D. 2008. Managers' implicit assumptions about personnel. Current Directions in Psychological Science, 17: 219-223.

Hofstede, G. 1980. Culture's consequences: International differences in work-related values. Beverly Hills, CA: Sage Publications.

Hogan, R. J., Curphy, G. J., \& Hogan, J. 1994. What we know about personality: Leadership and effectiveness. American Psychologist, 49: 493-504.

Jeffcoat, K. A. 2000. Multi-source feedback, source credibility, and performance discrepancy: The dynamics of fairness and usefulness perceptions. Dissertation Abstracts International, Section B: The Sciences and Engineering, 614-B, 2256.

Judge, T. A., LePine, J. A., \& Rich, B. L. 2006. Loving yourself abundantly: Relationship of the narcissistic personality to self- and other perceptions of workplace deviance, leadership, and task and contextual performance. Journal of Applied Psychology, 91: 762-776.

Kacmar, K. M., Bachrach, D. G., Harris, K. J., \& Zivnuska, S. 2011. Fostering good citizenship through ethical leadership: Exploring the moderating role of gender and organizational politics. Journal of Applied Psychology, 96: 633-642.

Kanungo, R. N., \& Mendonca, M. 1996. Ethical dimensions of leadership. Thousand Oaks, CA.: Sage Publications, Inc.

Kozlowski, S., \& Klein, K. 2000. A multilevel approach to theory and research in organizations: Contextual, temporal, and emergent processes. In K. J. Klein \& S. W. J. Kozlowski (Eds.), Multilevel theory, research, and methods in organizations: 3-90. San Francisco, CA: Jossey-Bass.

Lance, C. E., Butts, M. M., \& Michaels, L. C. 2006. The sources of four commonly reported cutoff criteria: What did they really say? Organizational Research Methods, 9: 202-220.

Lawrence, T. B., \& Robinson, S. L. 2007. “Ain't Misbehavin:” Workplace deviance as organizational resistance. Journal of Management, 33: 378-394.

Mayer, D. M., Kuenzi, M., \& Greenbaum, R. 2010. Examining the link between ethical leadership and employee misconduct: The mediating role of ethical climate. Journal of Business Ethics, 95: 7-16.

Mayer, D. M., Aquino, K., Greenbaum, R. L., \& Kuenzi, M. 2012. Who displays leadership and why does it matter? An examination of antecedents and consequences of ethical leadership. Academy of Management Journal, 55: 151-171.

Mayer, D. M., Kuenzi, M., Greenbaum, R., Bardes, M., \& Salvador, R. 2009. How does ethical leadership flow? Test of a trickle down model. Organizational Behavior and Human Decision Processes, 103: 1-13.

Mayer, D. M., Nurmohamed, S., Treviño, L. K., Shapiro, D. L., \& Schminke, M. 2013. Encouraging employees to report unethical conduct internally: It takes a village. Organizational Behavior and Human Decision Processes, 121: 89-103.

Meade, A. W., \& Craig, S. B. 2012. Identifying careless responses in survey data. Psychological Methods, 17: 437-455.

Messick, A. E., \& Bazerman, M. H. D. M. 1996. Ethical leadership and the psychology of decision-making. Sloan Management Review, 37: 9-22.

Moore, D. A. 2007. Not so above average after all: When people believe they are worse than average and its implications for theories of bias in social comparison. Organizational Behavior and Human Decision Processes, 102: 42-58. 
Moore, D. A., \& Small, D. A. 2007. Error and bias in comparative judgment: On being both better and worse than we think we are. Journal of Personality and Social Psychology, 92: 972-989.

Morgan, R. B. 1993. Self- and co-worker perceptions of ethics and their relationships to leadership and salary. Academy of Management Journal, 36: 200-214.

Moshavi, D., Brown, F. W., \& Dodd, N. G. 2003. Leader self-awareness and its relationship to subordinate attitudes and performance. Leadership and Organization Development Journal, 24: 407-418.

National Retail Federation. 2015. The 2015 national retail security survey. Washington, DC: National Retail Federation; Gainesville, FL: University of Florida.

Neeves, P., \& Story, J. 2015. Ethical leadership and follower organizational deviance: The moderating role of follower moral attentiveness. Journal of Business Ethics, 262: 190-203.

Ng, T. W. H., \& Feldman, D. C. 2015. Ethical leadership: Meta-analytic evidence of criterionrelated and incremental validity. Journal of Applied Psychology, 1003: 948-965

Nielsen, R., Marrone, J. A., \& Slay, H. S. 2010. A new look at humility: Exploring the humility concept and its role in socialized charismatic leadership. Journal of Leadership \& Organizational Studies, 171: 33-43.

Ou, A. Y., Tsui, A. S., Kinicki, A. J., Waldman, D. A., Xiao, Z., \& Song, L. J. 2014. Humble chief executive officers' connections to top management team integration and middle managers' responses. Administrative Science Quarterly, 59: 34-72.

Owens, B. P., \& Hekman, D. R. 2012. Modeling how to grow: An inductive examination of humble leader behaviors, contingencies, and outcomes. Academy of Management Journal, 554: 787-818.

Owens, B. P., Johnson, M. D., \& Mitchell, T. R. 2013. Expressed humility in organizations: Implications for performance, teams, and leadership. Organization Science, 245: 1517-1538.

Owens, B. P., Wallace, A. S., \& Waldman, D. A. 2015. Leader narcissism and follower outcomes: The counterbalancing effect of leader humility. Journal of Applied Psychology, 100: 1203-1213.

Potipiroon, B., \& Fellows, K. L. 2016. What difference do ethical leaders make?: Exploring the mediating role of interpersonal justice and the moderating role of public service motivation. International Public Management Journal, 192: 171-207.

Richardson, H., \& Vandenberg, R. 2005. Integrating managerial perceptions and transformational leadership into a work-unit level model of employee involvement. Journal of Organizational Behavior, 26: 561-589.

Robinson, S., \& Bennett, R. 1995. A typology of deviant workplace behaviors: A multidimensional scaling study. Academy of Management Journal, 38: 555-572.

Robinson, S., \& Bennett, R. 1997. Workplace deviance: Its definition, its manifestations, and its causes. Research on Negotiations in Organizations, 6: 3-27.

Robinson, S., \& O’Leary-Kelly, A. 1998. Monkey see, monkey do: The influence of work groups on the antisocial behavior of employees. Academy of Management Journal, 41: 658-672.

Ruben, B. D., \& Kim, J. Y. 1975. General systems theory and human communication. Rochelle Park, NJ: Hayden.

Ruben, B. D., \& Stewart, L. 2016. Communication and human behavior (6 $6^{\text {th }}$ ed.). London: Pearson.

Salancik, G. R., \& Pfeffer, J. 1978. A social information processing approach to job attitudes and task design. Administrative Science Quarterly, 23: 224-253. 
Schneider, B., White, S., \& Paul, M. 1998. Linking service climate and customer perceptions of service quality: Test of a causal model. Journal of Applied Psychology, 83: 150-163.

Sedikides, C., \& Gregg, A. P. 2008. Self-Enhancement: Food for thought. Perspectives on Psychological Science, 3: 102-16.

Simons, T. 2002. Behavioral integrity: The perceived alignment between managers' words and deeds as a research focus. Organization Science, 13: 18-35.

Szell, S., \& Henderson, R. 1997. The impact of self-supervisor/subordinate performance rating agreement on subordinates' job satisfaction and organizational commitment. Journal of Applied Social Behaviour, 3: 25-37.

Sosik, J. J. 2001. Self-other agreement on charismatic leadership: Relationships with work attitudes and managerial performance. Group and Organization Management, 26: 484-511.

Tappin, B. M., \& McKay, R. T. 2017. The illusion of moral superiority. Social Psychological and Personality Science, 8: 623-31.

Taylor, S. E., \& Brown, J. D. 1988. Illusion and well-being: A social psychological perspective on mental health. Psychological Bulletin, 103: 193-210.

Tenbrunsel, A. E., \& Bazerman, M. H. 2011. Ethical breakdowns. Harvard Business Review, 89: 58-65.

Tenbrunsel, A. E., Diekmann, K. A., Wade-Benzoni, K. A., \& Bazerman, M. H. 2010. The ethical mirage: A temporal explanation as to why we aren't as ethical as we think you we are. Research in Organizational Behavior, 30: 153-173.

Tracey, J. B., \& Tews, M. 2005. Construct validity of a general training climate scale. Organizational Research Methods, 8: 353-374.

Treviño, L. K., Brown, M., \& Hartman, L. P. 2003. A qualitative investigation of perceived executive ethical leadership: Perceptions from inside and outside the executive suite. Human Relations, 55: 5-37.

Treviño, L. K., Hartman, L. P., \& Brown, M. E. 2000. Moral person and moral manager: How executives develop a reputation for ethical leadership. California Management Review, 42: 128-142.

Treviño, L. K., Weaver, G. R., \& Brown, M. E. 2008. It's lovely at the top: Hierarchical levels, identities, and perceptions of organizational ethics. Business Ethics Quarterly, 18: 233-252.

Van Velsor, E., Taylor, S., \& Leslie, J. B. 1993. An examination of the relationships among self-perception accuracy, self-awareness, gender, and leader effectiveness. Human Resource Management, 32: 249-263.

Walumbwa, F. O., \& Schaubroeck, J. 2009. Leader personality traits and employee voice behavior: Mediating roles of ethical leadership and work group psychological safety. Journal of Applied Psychology, 94: 1275-1286.

Yammarino, F. J., \& Atwater, L. E. 1997. Do managers see themselves as others see them? Implications of self-other rating agreement for human resource management. Organizational Dynamics, 25: 35-44. 